\title{
TWENTY-FOUR HOUR BLOOD PRESSURE MONITORING IN WOMEN WITH GESTACIONAL DIABETES MELLITUS
}

SánchezŁechuga B1; López Tinoco, C1; López Ballesta, C1; Tamayo Serrato, JA1; Mateo Gavira, I1; Vilchez López, FJ1; Aguilar Diosdado, $\mathrm{M}^{1}$

1 UGC Endocrinología y Nutrición. H.U.Puerta del Mar. Cádiz.

\section{OBJECTIVES}

Gestational diabetes mellitus (GDM) is associated with an increased risk of pregnancy-induced hypertension (PIH). Ambulatory blood pressure monitoring (ABPM) has been used to screen for PIH and preeclampsia in normotensive type 1 diabetic women. To date, there are no data regarding ABPM in women with GDM. The aim of the study was to establish blood pressure (BP) profiles for pregnant with GDM, using ABPM and determine whether a BP pattern can define a population at risk for developing PIH. Furthermore, we analysed the relation between BP profiles and baseline characteristics, metabolic parameters, obstetrics and perinatal complications.

\section{METHODS}

We prospectively studied 62 normotensive women with GDM consecutively recruited at 26-32 weeks of pregnancy. ABPM was carried out for one 24-h period during second or third trimester on each patient, using the SPACELABS 90207 ABP monitor. Clinical and metabolic data, obstetric and perinatal outcomes were obtained. Based on nocturnal fall pattern, we established four subgroups: dippers, non-dippers, extreme dippers, and risers.

\section{RESULTS}

The mean age was $34 \pm 4.4$ years, BMI was $27 \mathrm{~kg} / \mathrm{m}^{2}$ and $\mathrm{HbA}_{1 \mathrm{C}} 5.05 \%$. Forty-five percent of the patients had a family history of Type 2 Diabetes; and $33.9 \%$ of high blood pressure. Recordings with $>25 \%$ of measurement errors were excluded from the analysis. The mean systolic/diastolic BP was $107.9 / 65.7 \mathrm{mmHg}$. By ABPM, 20 (41.7\%) patients were pattern dippers, 2 (4.2\%) extreme dippers, 20 (41.7\%) non-dippers, and $6(12.5 \%)$ risers. Comparing dipper/non-dippers groups with baseline and metabolic characteristics, $24 \mathrm{hr}$ microalbuminuria excretion was significantly higher in the dipper group (0.56 vs $2.03 \mathrm{ng} / \mathrm{ml}$, $P<0.05)$. We observed higher levels of night-time diastolic BP in non-dippers $(62.9 \mathrm{vs} 56.4 \mathrm{mmHg})$. Fifty-one women delivered to date, $5.8 \%$ had preeclampsia and $7.8 \%$ PIH. Twenty five percent of women had caesarean delivery and $17.6 \%$ macrosomia, without significant differences between dipper/non-dipper groups.

\section{Figure 1. Distribution by dippers/non-dippers groups.}

Table 1. Baseline and metabolic characteristics.

\begin{tabular}{|l|c|}
\hline & MEAN \pm SD \\
\hline Age (years) & $34 \pm 4.4$ \\
\hline Weight $(\mathrm{kg})$ & $71 \pm 14.1$ \\
\hline BMI $\left(\mathrm{kg} / \mathrm{m}^{2}\right)$ & $27 \pm 5.05$ \\
\hline Uric acid $(\mathrm{mg} / \mathrm{dl})$ & $3.6 \pm 0.86$ \\
\hline HbAic $(\%)$ & $5.05 \pm 0.48$ \\
\hline Total cholesterol $(\mathrm{mg} / \mathrm{dl})$ & $251.3 \pm 41.1$ \\
\hline Triglycerides $(\mathrm{mg} / \mathrm{dl})$ & $188.9 \pm 61.5$ \\
\hline Systolic BP $(\mathrm{mmHg})$ & $107.9 \pm 10.7$ \\
\hline Diastolic BP $(\mathrm{mmHg})$ & $65.7 \pm 9.3$ \\
\hline & MEDIAN / RANGE \\
\hline Urine microalbuminuria $(\mathrm{mg} / \mathrm{dl})$ & $0.4 /$ o.o -25.7 \\
\hline Microalbuminuria/creatinine & $4.1 /$ o.o - 216.9 \\
(mg/dl) & $\mathbf{n}(\%)$ \\
\hline Family history of DM & $28(45.2)$ \\
\hline Family history of HBP & $21(33.9)$ \\
\hline
\end{tabular}

\section{CONCLUSIONS}

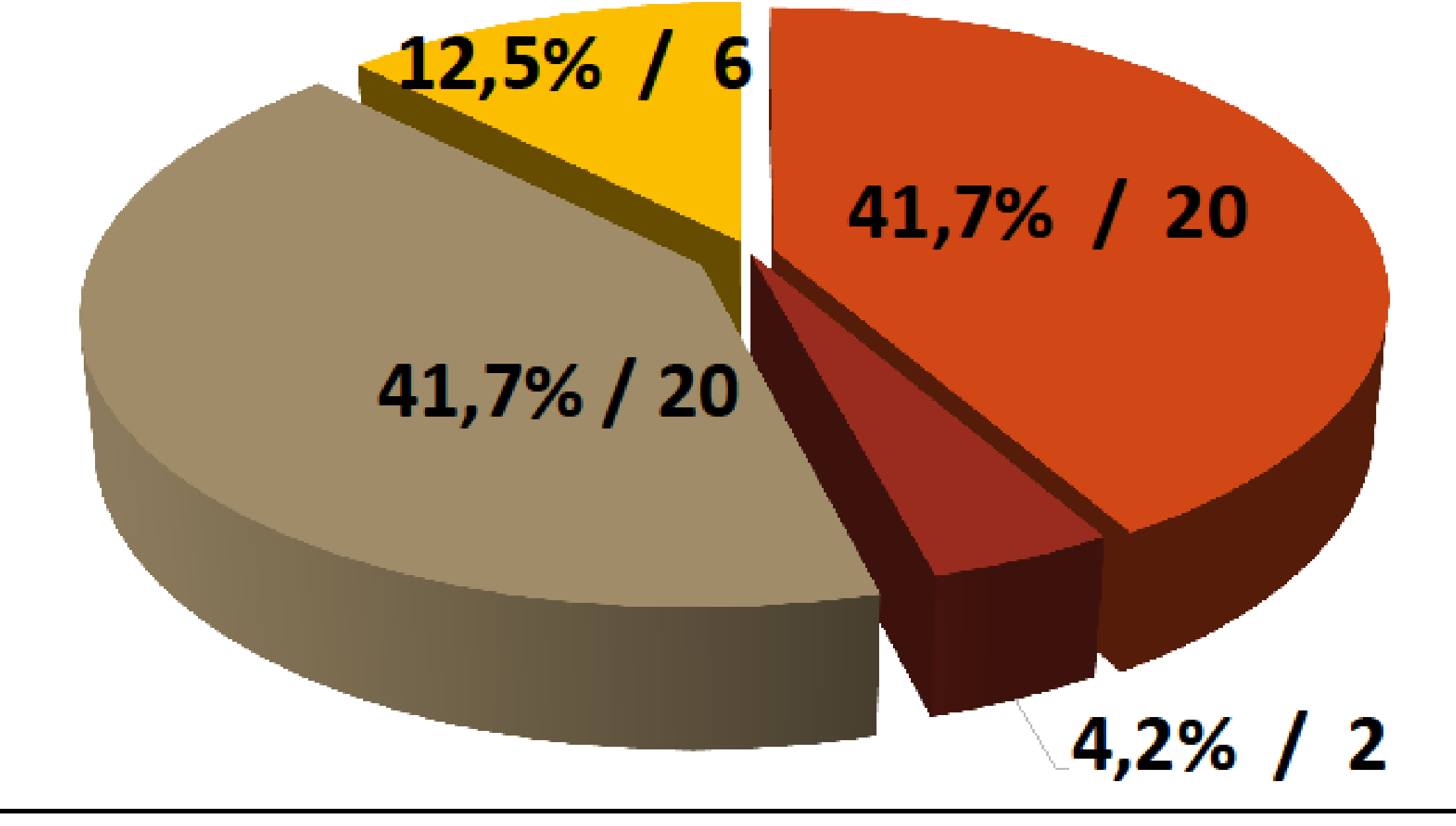

Tabla 2. Bivariant analysis of dipper/non-dippers groups with baseline and metabolic characteristics.

\begin{tabular}{|l|c|c|c|}
\hline & \multicolumn{1}{|l|}{$\begin{array}{l}\text { DIPPER } \\
\text { PATTERN }\end{array}$} & $\begin{array}{l}\text { NON DIPPER } \\
\text { PATTERN }\end{array}$ & P value \\
\hline Age (years) & $34.8 \pm 3.6$ & $34.3 \pm 4.2$ & 0.61 \\
\hline 24 hours microalbuminuria & $0,56 \pm 0.63$ & $2.03 \pm 5.5$ & $\mathbf{0 , 0 2}$ \\
\hline Family history of HBP & $9(40 \%)$ & $7(26 \%)$ & 0,1 \\
\hline Family history of DM & $10(45 \%)$ & $10(38 \%)$ & 0,6 \\
\hline BMI (kg/m $)$ & $25.8 \pm 4.3$ & $26.9 \pm 5.3$ & 0.35 \\
\hline Systolic BP (mmHg) & $108.5 \pm 10.9$ & $107.4 \pm 11.5$ & 0.95 \\
\hline Diastolic BP (mmHg) & $65.05 \pm 6.4$ & $66.3 \pm 8.5$ & 0.2 \\
\hline HbAic (\%) & $5.05 \pm 0.42$ & $5.03 \pm 0.46$ & 0.75 \\
\hline
\end{tabular}

$8(36 \%)$

$13(50 \%)$
- Dipper pattern

- Extreme dipper pattern

Non - dipper pattern

Riser pattern

We concluded, that a higher rate of the non-dippers pattern were observed in women with GDM and it seems to be associated with other factors, such as $24 \mathrm{~h}$ microalbuminuria excretion. Thus, higher levels of night-time systolic/diastolic BP could be a useful predictor of PIH. Further studies will be needed to determine the relationships across of BP alterations and baseline and metabolic characteristics, and obstetrics and perinatal outcomes. 